\title{
High cervical commissural myelotomy in the treatment of pain
}

\author{
I. PAPO AND A. LUONGO
}

From the Neurosurgery Division, Regional General Hospital, Ancona, Italy

SYNOPSIS High cervical myelotomy was carried out on 10 patients. Commissurotomy was performed at the $\mathrm{C}_{1-3}$ level by a combined procedure of deep electrocoagulation and sharp splitting of the posterior columns. The immediate results were excellent in all patients, but relapse of pain took place shortly in six of them; there was apparently no relation with the location of pain. No long-term favourable results were observed in this series. Only three patients exhibited a well-defined band of mild hypalgesia from $C_{2}$ to $T_{10}$ dermatome, but it lasted for only three to four weeks. Transient lower or four limb ataxia was observed in seven patients. Different pain conducting systems seem to be affected by commissural myelotomy, but not to a sufficient extent to give permanent or longlasting relief of pain. The indications for high cervical myelotomy are very limited: this procedure should be considered only in patients with unilateral or bilateral arm and/or upper chest pain, respiratory impairment, and short life expectancy.

Spinal commissurotomy for the treatment of pain has a very long history. The procedure was suggested by Greenfield in 1926 and the first operation was carried out by Armour in 1927. Subsequently Putnam (1934) performed cervical myelotomy on three patients for pain located in the arms and in the shoulders. Myelotomy was carried out at lumbar level in 1928 by Leriche, but his experience was reported only in 1936.

The procedure was later applied on a large scale by French authors (Mansuy et al., 1944; Guillaume et al., 1945; Wertheimer and Sautot, 1949; Wertheimer and Lecuire, 1953). Wertheimer and Lecuire (1953) surveyed the whole experience of the Lyons group: altogether 107 patients were operated upon (some of them had previously been reported by Mansuy et al., and by Wertheimer and Sautot), the incision level was $\mathrm{T}_{4}-\mathrm{T}_{6}$ cord segment, and the depth of the cut only $3.0 \mathrm{~mm}$. Although the percentage of good and fair results was quite impressive, the procedure was abandoned even by Wertheimer's group and unilateral or bilateral cordotomy almost always preferred. At the same time (1952)

(Accepted 22 March 1976.)
Arutjunov reported on 15 patients treated by spinal myelotomy performed at $T_{9}-T_{12}$ segments with good results.

After isolated cases (Ballantine and Bertrand, cited by Richards et al. (1966)) or small series (Lembke, 1964), myelotomy was again strongly advocated for the treatment of pain in the lower part of body by Sourek (1967) who operated on 25 patients, with good results in 22 , without complaint of any major untoward effects. Thereafter the same technique was used by Broager (1974) and by Lippert et al. (1974).

In 1970, Hitchcock suggested a new approach: the percutaneous high cervical myelotomy. This technique was first devised for the treatment of shoulder, arm, and upper chest pain from bronchial carcinoma. Although such pain may be relieved by high cervical cordotomy, preoperative impairment of respiratory function entails a high rate of respiratory complications, due to injury of descending pathways (Belmusto et al., 1963; Hitchcock and Leece, 1967). But by interrupting the spinal commissure at the first cervical segment, Hitchcock noticed that lower body pain was relieved as well. In 1974 Hitchcock published his results in a series of 26 patients. 
Stereotactic myelotomy was also performed by Schvartz (1974) and by Nadvornik et al. (1974).

Personally, we have been very impressed with the results published by Hitchcock and Schvartz. We have therefore carried out high cervical myelotomy, with a modified technique, in a series of selected patients. We chose some patients with unilateral or bilateral upper chest, arm, and shoulder pain, and some patients with diffuse pain in the sacral region and in both lower limbs, in whom bilateral cordotomy would have been needed.

\section{METHOD}

ANATOMICAL LANDMARKS According to the topometrical maps published by Taren et al. (1969) and Zlatos et al. (1971) at high cervical level $\left(C_{1-4}\right)$ the central canal lies at a depth of $6.0 \mathrm{~mm}$ from the surface of the posterior aspect of the spinal cord. The white commissure lies at a depth of $6.5 \mathrm{~mm}$ and the anterior spinal fissure at a depth of $7.5 \mathrm{~mm}$.

EQUIPMENT We have used the OWL cordotomy set. The insulated probe bears an exposed coagulating tip $2.5 \mathrm{~mm}$ long and $0.4 \mathrm{~mm}$ in diameter.

TECHNIQUE Under general anaesthesia a standard laminectomy is carried out at $\mathrm{C}_{1-3}$ cord segment. Under magnification the midline is identified: sometimes a midline arachnoid septum is clearly visible. Sometimes the tortuous longitudinal vein can be pulled aside but more often it must be coagulated with a bipolar electrocautery. The pia mater in the midline is coagulated and cut with microscissors over three spinal segments, between the upper posterior rootlet of $\mathrm{C}_{2}$ and the lower one of $\mathrm{C}_{4}$ segment. At different levels six to seven coagulations are performed with the tip of the coagulating electrode at a depth of $6 \mathrm{~mm}$. The electrical parameters are the same as for percutaneous cordotomy: $30 \mathrm{~mA}$, 20-25 V, 30 seconds. Subsequently, the posterior columns are split over the whole length between $\mathrm{C}_{2}$ and $\mathrm{C}_{4}$ segments with a microsurgery right-angled hook up to a depth of about $5 \mathrm{~mm}$. By this combined procedure a complete high cervical myelotomy over three segments can be achieved, avoiding the risk of injuring the anterior spinal artery.

\section{RESULTS}

Our results are summarized in the Table. In all the patients the immediate results were excellent: pain was completely relieved.
Unfortunately, complete relief was too often very brief, in five patients it lasted only two to four weeks. Severe pain relapse took place in six patients within two months. The only noncancer patient, who had complained of excruciating pain from avulsion of the brachial plexus, died from cardiocirculatory failure eight weeks after the operation, remaining almost pain-free until his death. Another patient (case 10), with upper arm and upper chest pain from bronchial carcinoma, died pain-free, but he survived only five weeks. Two other patients were fairly well relieved until their death three months after the operation. But in one of them (case 7) a severe spinal cord compression from metastatic carcinoma developed in the last weeks, in the other (case 8) unilateral spinothalamic cordotomy was associated during the same operation.

Respiratory and bladder troubles were never observed in our patients. Sensory changes are, by contrast, worth commenting on. In spite of the fact that the operative procedure is not traumatic, the posterior columns are very often involved; in almost all patients temporary ataxia (in lower or in four limbs) takes place, disappearing in three to four weeks. Two patients noticed paraesthesia in the lower limbs. In one patient (case 3), in whom the lesion was a little bit too lateral, the right posterior column was injured. This patient complained permanently of very distressing tingling dysaesthesia in the right half of the body. In this side of the body primary pain was abolished but it remained unmodified on the left side.

In three patients we were able to demonstrate a well defined band of mild hypalgesia from $\mathrm{C}_{2}$ to $\mathrm{T}_{10}$ dermatomes. All changes in pain sensation were transient, wearing off in about three weeks.

\section{DISCUSSION}

After the first results related by Putnam (complete relief in one patient, incomplete relief in one, and death in one), the French authors of the Lyons group in their first overall survey (Wertheimer and Lecuire, 1953) noted good results in about two-thirds of patients. Nevertheless, Dargent et al. (1963), on the basis of the same material, revised critically 10 years later, 
TABLE

CLINICAL DETAILS

\begin{tabular}{|c|c|c|c|c|c|c|c|}
\hline Patient & $\begin{array}{c}\text { Age } \\
(y r)\end{array}$ & Primary disease & Pain reference & Results & Follow-up & Sensory changes & Further treatment \\
\hline 1. O.A. & 55 & Lung carcinoma & $\begin{array}{l}\text { Bil. upper chest } \\
\text { and upper } \\
\text { limbs }\end{array}$ & $\begin{array}{l}\text { Complete relief } \\
4 \mathrm{w} ; \text { partial } \\
\text { relief } 4 \mathrm{w} \text {; pain } \\
\text { relapse } 2 \mathrm{~m}\end{array}$ & $4 \mathrm{~m}$ & $\begin{array}{l}\text { Transient lower } \\
\text { limb ataxia. } \\
\text { Transient } C_{2}-T_{10} \\
\text { hypalgesia }(3 \mathrm{w})\end{array}$ & - \\
\hline 2. G.G. & 63 & Breast carcinoma & $\begin{array}{l}\text { L. upper limb, } \\
\text { L hemithorax }\end{array}$ & $\begin{array}{l}\text { Complete relief } \\
4 \mathrm{w} ; \text { partial } \\
\text { relief } 6 \mathrm{w}\end{array}$ & Dead at $3 \mathrm{~m}$ & $\begin{array}{l}\text { Transient lower } \\
\text { limb ataxia. } \\
\text { Transient } C_{2}-T_{10} \\
\text { hypalgesia }\end{array}$ & - \\
\hline 3. G.M. & 46 & $\begin{array}{l}\text { Sacral malignant } \\
\text { teratoma }\end{array}$ & $\begin{array}{l}\text { Sacral region } \\
\text { testes. } \\
\text { Lower limbs }\end{array}$ & $\begin{array}{l}\text { Complete relief } \\
3 \mathrm{w} \text {; pain } \\
\text { relapse } 1 \mathrm{~m}\end{array}$ & $1 \mathrm{yr}$ & $\begin{array}{l}\text { Transient four } \\
\text { limbs ataxia } \\
\text { (4 w) } R \\
\text { permanent } \\
\text { touch-deep } \\
\text { hypaest and } \\
\text { painful tingling } \\
\text { paraesthesia in } \\
\text { lower limbs }\end{array}$ & $\begin{array}{l}\text { Phenol rhizotomy, } \\
\text { pain relieved } \\
\text { (paraparesis and } \\
\text { urinary } \\
\text { retention) } \\
\text { follow-up } 3 \mathrm{~m}\end{array}$ \\
\hline 4. A.E. & 43 & Cervical carcinoma & Perineum & $\begin{array}{l}\text { Complete relief } \\
2 \mathrm{w}\end{array}$ & $6 \mathrm{~m}$ & None & $\begin{array}{l}\text { Phenol rhizotomy } \\
\text { pain relieved } \\
\text { follow-up } 4 \mathrm{~m}\end{array}$ \\
\hline 5. S.N. & 60 & Rectal carcinoma & $\begin{array}{l}\text { Perineum sacral } \\
\text { region lower } \\
\text { limbs }\end{array}$ & $\begin{array}{l}\text { Partial relief } 8 \mathrm{w} ; \\
\text { pain relapse } 2 \mathrm{~m}\end{array}$ & Dead at $4 \mathrm{~m}$ & $\begin{array}{l}\text { Transient four } \\
\text { limbs ataxia. } \\
\text { Transient } C_{2}-T_{10} \\
\text { hypalgesia }(4 \mathrm{w})\end{array}$ & - \\
\hline 6. B.O. & 54 & Lung carcinoma & R. hemithorax & $\begin{array}{l}\text { Complete relief } \\
3 \mathrm{w}\end{array}$ & $3 \mathrm{~m}$ & $\begin{array}{l}\text { Transient lower } \\
\text { limb ataxia }(3 \mathrm{w})\end{array}$ & - \\
\hline 7. C.C. & 46 & Rectal carcinoma & $\begin{array}{l}\text { Sacral region } \\
\text { perineum lower } \\
\text { limbs }\end{array}$ & $\begin{array}{l}\text { Pain relief up to } \\
\text { death at } 3 \mathrm{~m}\end{array}$ & Dead at $3 \mathrm{~m}$ & $\begin{array}{l}\text { Transient lower } \\
\text { limb ataxia with } \\
\text { paraesthesia } \\
(3 \text { w). } \\
\text { Paraparesis } \\
\text { worsened }\end{array}$ & 一 \\
\hline 8. D.P. & 65 & Kidney carcinoma & Lower limbs & $\begin{array}{l}\text { Pain relief up to } \\
\text { death at } 3 \mathrm{~m}\end{array}$ & Dead at $3 \mathrm{~m}$ & None & $\begin{array}{l}\text { Unilateral } \\
\text { cordotomy by } \\
\text { the same } \\
\text { surgical } \\
\text { procedure }\end{array}$ \\
\hline & 44 & $\begin{array}{l}\text { Brachial plexus } \\
\text { avulsion }\end{array}$ & L. upper limb & $\begin{array}{l}\text { Complete relief up } \\
\text { to death at } 9 \mathrm{w}\end{array}$ & Dead at $9 w$ & $\begin{array}{l}\text { Transient four } \\
\text { limbs ataxia (4 w) }\end{array}$ & - \\
\hline 10. G.Z. & 64 & Lung carcinoma & $\begin{array}{l}\text { L upper limb. } \\
\text { L hemithorax }\end{array}$ & $\begin{array}{l}\text { Complete relief up } \\
\text { to death at } 5 \mathrm{w}\end{array}$ & Dead at $5 \mathrm{w}$ & None & - \\
\hline
\end{tabular}

conclude that spinal myelotomy is effective only for the treatment of vaginal and visceral pelvic pain, while rectal and lower limb pains are not relieved. In their opinion, unilateral or bilateral cordotomy should be preferred.

Sourek $(1967,1969)$, by his complete commissural myelotomy, relieved satisfactorily 22 out of 25 patients operated upon. In three patients pain persisted, but with quite different character. In most patients treated by Sourek long-term follow-up could not be carried out because of their poor conditions ( 19 were cancer patients). Three patients were followed up for six, 12, and 36 months respectively and no recurrence of pain was found. In all three patients hypaesthesia or paraesthesia in the lower limbs was permanent.
By the same technique, Broager (1974) treated 34 patients. His experience can be summed up as follows: permanent excellent results (until death of the patients) were seen in 16 patients; temporary excellent results followed by recurrence of pain were seen in nine patients; permanent good results in three patients; and continuous poor results were seen in five patients, two having painful dysaesthesia instead of the original pain, and three continuous pains. There was one postoperative death. Recurrence of pain took place after periods of one to six months. Lippert et al. (1974) operated on 16 patients. Relief was excellent in 10 patients, without recurrence after one to seven months, good in five, and poor in one. In this series the results were gratifying in the treatment of pain in the midline or in 
bilaterally innervated structures, but much less effective in spinal and lower limb pains.

As far as cervical stereotactic myelotomy is concerned, Hitchcock (1974) summed up his experience: in five patients the treatment was abandoned because of technical difficulties, two patients were lost to follow-up. Of the remaining 19 the results were considered as excellent in eight patients, who had complete relief until death or the last follow-up $(10,26,26,28$ days; two, four, six months, and four years respectively). Six of these patients had marked sensory changes. Pain relief was good in five patients (seven days, two, two, five, 17 months). Four of these patients had marked sensory changes. Poor relief was achieved in four patients, where relief was brief and subsequent surgery or strong analgesics were required. Only one patient of this group had sensory changes. No relief was obtained in two patients.

Schvartz (1974) operated on 14 cancer and three neurological patients. The results were excellent in all the neurological patients, excellent in 10, good in two, and fair in two cancer patients. Follow-up ranged between five and 12 months for the benign conditions and two and five months for the neoplastic patients.

Spinal commissurotomy was first carried out with the aim of interrupting bilaterally the spinothalamic fibres innervating the area involved by pain. However, with the former technique, the incision was too distant from the area relieved and not deep enough to divide the anterior commissure. This goal, however, was achieved by the more complete procedure advocated by Šourek (1967). But even after this complete longitudinal splitting of the spinal cord over 3-3.5 cm at appropriate level, sensory changes are very slight (Šourek, 1967; Broager, 1974; Lippert et al., 1974). Hence the most important role in relieving pain should not be played by the section of the spinothalamic pathways at the anterior spinal commissure.

Sourek (1967) felt that spinal commissurotomy does interrupt both systems conducting pain: the slow-conducting anterolateral system and the fast-conducting mediodorsal system. This latter would have a somatotopic arrangement and would run in the medial portion of the posterior columns.

Broager (1974) points out that myelotomy produces a rather diffuse lesion, as coagulation of the tortuous dorsal veins causes changes of vascularization of the dorsal funiculi, splitting of the posterior part of the spinal cord, even kept carefully in the midline, cannot avoid damaging the medial portion of the posterior columns, and, finally, division of both the posterior and the anterior commissure eliminates all crossing impulses over a distance corresponding to the length of the incision.

According also to Lippert et al. (1974) a painmodulating mechanism located in the posterior columns is likely to play a role. Hitchcock (1974) suggests that the effects of cervical commissurotomy are to destroy decussating spinothalamic fibres from the upper part of the body, which would seem to lie closer to the central part of the spinal cord than was generally realized, during their decussation. An explanation for the loss of pain in the lower part of the body would be to postulate an entirely separate, purely pain conducting pathway, ascending the spinal cord possibly multisynaptically close to the midline.

Experimentally Davis et al. (1929) described crossed and uncrossed pain pathways ascending close to the grey matter, up to the upper cervical cord and lower medulla oblongata where they cross. Shealy et al. (1966) have recorded evoked potentials from $\mathrm{C}$ fibres in the central cord and Richards et al. (1966) have also demonstrated the presence of uncrossed pain fibres. Schvartz (1974), who was not able to demonstrate any sensory losses, contends that the rationale of commissurotomy consists in placing a predominantly selective lesion in the extralemniscal system. He also defines commissural myelotomy as 'extralemniscal myelotomy'.

Our anatomical knowledge of the effects of commissurotomy on the spinal cord ascending systems is very limited. Hitherto, only the experimental work published by Kerr and Lippman (1974) is available. According to Kerr and Lippman's findings in monkeys, projections to the periaqueductal grey matter seen in cordotomies are topographically different from those seen in myelotomies. In cordotomy material, degeneration of moderate intensity is seen in the subnucleus lateralis of the periaqueductal grey matter and it is located immediately medial to the mesencephalic nucleus of the fifth nerve. After myelotomy the degeneration is quite 
specifically distributed to the most ventrolateral part of the periaqueductal grey matter, and when the nucleus of Darckschewitz is present, it terminates throughout it. When this nucleus disappears the degeneration continues to be present in this ventrolateral position and it can be followed in the same location into the posterior hypothalamic area. Thus, a long column of cells extending through the rostral half of the ventral periaqueductal grey matter receives crossed input from the spinal cord.

To Kerr and Lippman the fact that the projection to the most ventrolateral aspect of the periaqueductal grey matter is present only in myelotomy material indicates that the ascending fibres must run in an area of the cord other than that transected by anterolateral cordotomy. It raises the interesting but speculative issue that it might be responsible for return of pain after cordotomy or for the failure of cordotomy to reduce certain types of pain, such as phantom limb pain, pain of brachial plexus avulsion, or tabetic crisis. It must also be borne in mind that, at least in open myelotomy, factors related to the surgical procedure itself may play a role. Kerr and Lippman in their monkeys observed severe postoperative oedema extending for a number of segments caudal or rostral to the end of the incision.

Therefore functional troubles due to the oedema of the posterior part of the spinal cord are likely to occur in the first days or weeks after the operation: In our experience, sensory changes due to involvement of dorsal funiculi took place in almost all the patients, wearing off in three to four weeks. Wher ataxia and paraesthesia faded away in our cases, pain usually relapsed. We would also point out that in Šourek's patients, in whom the longest relief was achieved, hypalgesia and paraesthesia in the lower limbs were permanent. In our case 3 , in whom the injury of the right posterior funiculus caused permanent dysaesthesia, pain was abolished in the corresponding half of the body. Hence it would seem likely that the posterior column lesion plays a definite role in relieving pain. This effect might be twofold: on the one hand by interrupting the fast-conducting system, as suggested by Šourek (1974), and on the other hand by stimulating chronically the dorsal funiculi and inhibiting the primary pain.
Some fibres of the spinothalamic system are interrupted as well, but this amount does not seem to be relevant. So, as usually occurs after stereotactic medial thalamotomy (CM and Pf), which yields similar results, in most cases welldefined changes of pain sensation cannot be demonstrated. Multisynaptic ascending pain pathways are probably also involved by commissurotomy.

To summarize, we feel that, in cervical myelotomy carried out by us, different ascending pathways have been interrupted. Nevertheless, this procedure is not sufficient to ensure permanent or long-lasting relief, for when the effects of surgical trauma disappear and some fibres not anatomically divided are able to recover their function, pain usually recurs, no matter what its location.

\section{CONCLUSIONS}

Our experience with a small series of patients treated by high cervical commissural myelotomy is rather disappointing. As only short relief can be achieved, we think that cervical myelotomy has indeed very limited indications. We feel, however, that in some cases of unilateral or bilateral arm, shoulder, and upper chest pain, particularly when respiratory function is already impaired and life expectancy is short, cervical myelotomy might be considered. For pain located elsewhere more valuable techniques are available. The mechanism of action of myelotomy still remains unexplained. Many ascending systems seem to be involved, but, at least at cervical level, the reduced input of pain impulses brought about by this procedure is not enough to ensure permanent or long-lasting relief.

Our experience of dorsal myelotomy by the method of Šourek (1967) is limited. We are therefore unable to appraise its effectiveness in pain management.

\section{REFERENCES}

Armour, D. (1927). Lettsomian Lecture on the surgery of the spinal cord and its membranes. Lancet, 1, 691-697.

Arutjunov, A. I. (1952). Surgical cure of intractable pain by commissurotomy. Vrachebnoe Delo, 2, 117-122 (in Russian). 
Ballantine, H. T. Jr. Presented at meeting of Society of Neurological Surgeons, Rochester, Minn. May 1964. Quoted by Richards et al. (1966).

Belmusto, L., Brown, E., and Owens, G. (1963). Clinical observations on respiratory and vasomotor disturbances as related to cervical cordotomy. Journal of Neurosurgery, 20, 225-232.

Bertrand, C. Personal communication to Richards et al. (1966).

Broager, B. (1974). Commissural myelotomy. Surgical Neurology, 2, 71-74.

Dargent, M., Mansuy, L., Colon, J., and De Rougemont, J. (1963). Les problèmes posés par la douleur dans l'évolution des cancers gynécologiques. Lyon Chirurgicale, 59, 62-83.

Davis, L., Hart, J. T., and Crain, R. C. (1929). The pathway for visceral afferent impulses within the spinal cord. Surgery, Gynecology, and Obstetrics, 48, 647-651.

Greenfield, J. G. quoted by Hitchcock (1974).

Guillaume, J., Mazars, G., and Valletau de Mouillac (1945). La myélotomie commissurale, Presse Medicale, 53, 666-667.

Hitchcock, E. (1970). Stereotactic cervical myelotomy. Journal of Neurology, Neurosurgery, and Psychiatry, 33, 224-230.

Hitchcock, E. (1974). Stereotactic myelotomy. Proceedings of the Royal Society of Medicine, 67, 771-772.

Hitchcock, E., and Leece, B. (1967). Somatotopic representation of the respiratory pathways in the cervical cord in man. Journal of Neurosurgery, 27, 320-329.

Kerr, F. W. L., and Lippman, H. H. (1974). The primate spinothalamic tract as demonstrated by anterolateral cordotomy and commissural myelotomy. In Advances in Neurology vol. 4, pp. 147-156. Edited by J. Bonica. Raven Press: New York.

Lembcke, W. (1964). Ueber die mediolongitudinale chordotomie im Halsmarkbereich. Zentblatt für Chirurgie, 89, 439-443.

Leriche, R. (1936). Du traitement de la douleur dans les cancers abdominaux et pelviens inopérables ou recidivés. Gazette des Hôpitaux, 109, 917-922.
Lippert, R. G., Hosobuchi, Y., and Nielsen, S. L. (1974). Spinal commissurotomy. Surgical Neurology, 2, 373-377.

Mansuy, L., Lecuire, J., and Acassat, L. (1944). Technique de la myélotomie commissurale postérieure. Journal de Chirurgie, 60, 206-213.

Nadvornik, P., Freglikh, and Shramka, M. (1974). First experience with stereotactic surgery of the spinal cord in treating pain. Voprosy Neurokhirurgii, 38, 46-49. (In Russian).

Putnam, T. J. (1934). Myelotomy of the commissure. A new method of treatment for pain in the upper extremities. Archives of Neurology and Psychiatry (Chic.), 32, 1189-1193.

Richards, D. E., Tyner, C. F., and Shealy, C. N. (1966). Focused ultrasonic spinal commissurotomy. Experimental evaluation. Journal of Neurosurgery, 24, 701707.

Schvartz, J. R. (1974). Spinal cord stereotactic surgery. In Recent Progress in Neurological Surgery, pp. 234 245. Edited by K. Sano and S. Ishii. Amsterdam, Excerpta Medica.

Shealy, C. N., Tyner, C. F., and Taslitz, N. (1966). Physiological evidence of bilateral spinal projections of pain fibers in cats and monkeys. Journal of Neurosurgery, 24, 708-713.

Sourek, K. (1967). Commissural myelotomy in the treatment of intractable pain. In Proceeding of the Third International Congress of Neurological Surgery. Edited by A. C. Devet, Excerpta Medica; Amsterdam.

Šourek, K. (1969). Commissural myelotomy. Journal of Neurosurgery, 31, 524-527.

Taren, J. A., Davis, R., and Crosby, E. C. (1969). Target physiology corroboration in stereotaxic cervical cordotomy. Journal of Neurosurgery, 30, 569-584.

Wertheimer, P., and Lecuire, J. (1953). La myélotomie commissurale postérieure. A propos de 107 observations. Acta Chirurgica Belgica, 52, 568-574.

Wertheimer, P., and Sautot, J. (1949). Les résultats de la myélotomie commissurale postérieure (à propos de 69 observations). Concours Médical, 71, 413-414.

Zlatos, J., Cierny, G., and Nadvornik, P. (1971). A coniribution to the topometry of the spinal cord. Confinia Neurologica, 33, 342-349. 